\title{
ASSESSMENT OF PROBLEMS DURING EXCLUSIVE BREAST FEEDING AMONG PRIMIPARA MOTHERS AT SRI GOKULAM HOSPITAL, SALEM, TAMILNADU \\ Mrs. Nivethitha Sivanandam ${ }^{*}$ | Dr. Muthumari. P $^{* *}$ \\ *Ph. D Scholar, Himalyan University, Arunachal Pradesh, India. \\ ** Research Guide \& ${ }^{*}$ Vice Principal, Suran College of Nursing, Rajapalayam, Tamilnadu, India. DOI: http://doi.org/10.47211/tg.2020.v07iws01.006
}

Received $15^{\text {th }}$ June 2020, Accepted $22^{\text {nd }}$ June 2020, Available online $30^{\text {th }}$ June 2020.

\section{ABSTRACT:}

Mothers are recommended to exclusively breastfeed their infants for the first six months of their lives. This study determined to assess the problems associated with exclusive breast feeding (EBF) of primipara mothers. A descriptive design using purposive sampling technique of 100 primipara mothers having one year infant were selected from the study population. Ethical aspects maintained thro ughout the study. Data was collected using practice questionnaire and data was analyzed using descriptive statistics. The major findings identified were pressure from family and friends to bottle feed 26\%, taboos for lactating mothers to avoid water and certain foods accounts 30\%, $27 \%$ mothers reported interference from mother in law to administer water as a major socio-cultural problem they faced, while psychological problems encountered ranged from worry and stress of feeding at all times even at night (42\%), having to breastfeed even in public places (84\%), fear that the baby might not be getting enough nutrients (61\%). From the findings of the study, it is clear that breastfeeding mothers face a lot of problems in their attempt to carry out exclusive breast-feeding.

KEYWORDS: Infant nutrition, breastfeeding, exclusive breastfeeding, problems encountered.

\section{ABOUT AUTHORS}

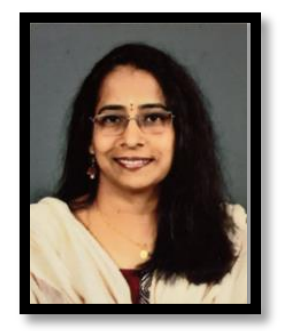

Mrs. Nivethitha Sivanandam is a Ph.D Scholar at Himalayan University, works as nursing chief at Sri Gokulam Hospital, Salem. She has been the speaker in several seminars \& conferences, private lactation consultation around Salem area.

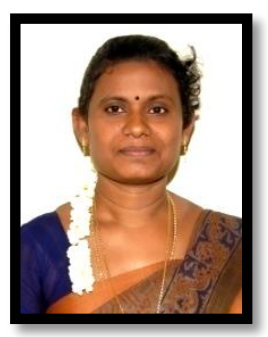

Dr. Muthumari. P is Vice Principal, Suran College of Nursing, Pillayarkulam. She has published paper in various National and International Journals and Organized various workshops and conferences. 


\section{INTRODUCTION:}

Exclusive breast-feeding is internationally the preferred way of feeding infants during the first 6 months of their lives, and is recognized as being one of the most natural and best forms of preventive medicine (WHO, 2002). Early and exclusive breastfeeding is widely regarded as an important intervention that reduces neonatal, infant, and child mortality, and remains a basis for child survival strategies. Breastfeeding is the cornerstone for child survival as poor breastfeeding practices contribute to 20 per cent of neonatal deaths and nearly 13 per cent of deaths in children below five years. If all children receive the benefits of breastfeeding then globally, 8, 23,000 child deaths can be averted every year UNICEF (2016).

Breast milk contains all the nutrients an infant need in the first six months of life. Exclusive breast feeding means that the infant receives only breast milk WHO (2019). In India, breastfeeding can reduce 1,56,000 child deaths every year; reduce over 3.4 million episodes of respiratory infections and 3.9 million episodes of diarrhea in young children UNICEF (2016).

According to UNICEF, Breastfeeding is not the sole responsibility of a mother. Government leadership and support from health systems, families, communities and workplaces can help a mother breastfeed successfully. Building communication and counselling skills of facilities and community healthcare providers, provision of counselling on breastfeeding during the antenatal period, at the time of delivery, other health contacts, and during home visits, are essential for promoting, supporting and protecting breastfeeding UNICEF (2016).

\section{STATEMENT OF PROBLEM:}

A descriptive study to assess the problems experienced during exclusive breast feeding among primipara mothers at Sri Gokulam hospital, Salem, Tamilnadu.

\section{OBJECTIVES:}

To assess the Problems during Exclusive breast feeding among primipara mothers.

\section{MATERIALS \& METHODS:}

A descriptive design was adopted for this study. Mothers attending the immunization clinic in Sri Gokulam hospital were included in the study. The study population consisted of 100 primipara mothers who attended the immunization clinic at this hospital during the period of study were recruited through non-probability purposive sampling method using inclusion criteria those exclusive breast feeding having infants up to 1 year on exclusive breast feeding for 1 month to 6 months who are willing to participate in the study. Data were collected by practice questionnaire on problems related to exclusive breast feeding.

Data was analyzed by descriptive statistical analysis and converted to frequencies and percentages.

\section{RESULTS \& DISCUSSION:}

The present study revealed demographic characteristics that most of the mothers were from Hindu religion $(74 \%)$, home makers $(78 \%)$ and $(82 \%)$ in rural communities. Most of the mothers belong to nuclear family $(57 \%)$ in urban community.

With regard to obstetrical variables majority of the mothers delivered above 37 weeks of gestation (83\%). More than half of the mothers delivered through cesarean section (57\%) whereas $54 \%$ of the mothers delivered through normal vaginal delivery.

Most of the mothers (40\%) knew that feeding with only breast milk without the addition of water or food for six months denotes EBF, (33\%) mothers believed that giving water once in a while to baby is also meant as EBF, while (8\%) women expressed no knowledge of EBF. (78\%) women reported interference from mothers-in-law to give water as a major socio-cultural problem they faced, while psychological problems encountered ranged from worry and stress of feeding at all times even at night (52\%), having to breastfeed even in public places (82\%), fear that the baby might not be getting enough nutrients (71\%). 


\section{ARTICLES}

Table 1. Frequency and Percentage distribution of the Infant variables of Primipara mothers $(\mathrm{N}=100)$

\begin{tabular}{|c|c|c|c|}
\hline S. No. & Infant Variables & $f$ & $\%$ \\
\hline \multirow[t]{7}{*}{1.} & Current age of the baby & & \\
\hline & 7 months & 32 & 32 \\
\hline & 8 months & 13 & 13 \\
\hline & 9 months & 12 & 12 \\
\hline & 10 months & 49 & 49 \\
\hline & 11 months & 03 & 3 \\
\hline & 12 months & 20 & 20 \\
\hline \multirow[t]{4}{*}{2.} & Weight of the baby at birth & & \\
\hline & $<2.5 \mathrm{Kg}$ & 26 & 26 \\
\hline & $2.6-3.5 \mathrm{Kg}$ & 23 & 23 \\
\hline & $>3.5 \mathrm{Kg}$ & 51 & 51 \\
\hline \multirow[t]{7}{*}{3.} & Current weight of the baby & & \\
\hline & $<3 \mathrm{Kg}$ & - & - \\
\hline & $3.1-4.9 \mathrm{Kg}$ & 15 & 15 \\
\hline & $5-6.9 \mathrm{Kg}$ & 35 & 35 \\
\hline & $7-8.9 \mathrm{Kg}$ & 2 & 2 \\
\hline & $9-10.9 \mathrm{Kg}$ & 48 & 48 \\
\hline & $>11 \mathrm{Kg}$ & - & - \\
\hline \multirow[t]{7}{*}{4.} & Current diet of your baby & & \\
\hline & Breast milk & 24 & 24 \\
\hline & Other milk & 47 & 47 \\
\hline & Both Breast milk and other milk & 08 & 08 \\
\hline & Breast milk with other foods & 21 & 21 \\
\hline & Bottle milk with other foods & - & - \\
\hline & Both Breast milk \& Bottle milk with other foods & - & - \\
\hline \multirow[t]{5}{*}{5.} & Age at weaning period & & \\
\hline & 4 months & 29 & 29 \\
\hline & 5 months & 18 & 18 \\
\hline & 6 months & 21 & 21 \\
\hline & After 6 months & 32 & 32 \\
\hline
\end{tabular}

The data in table 1 reveals that most of the baby's current age was 10 months (49\%). More than half of the babies birth weight was more than $3.5 \mathrm{Kg}(51 \%)$. With regard to current diet of the baby, more than half of the babies are given other milk (47\%). With regard to weaning, most of the mothers started weaning their baby after 6 months of their child's age (32\%).

Interference from mother in law to... culture of not giving water

Pressure from family/friends on bottle...

Wrong information from family/friends

Taboo for a lactating mother

Superstitious beliefs

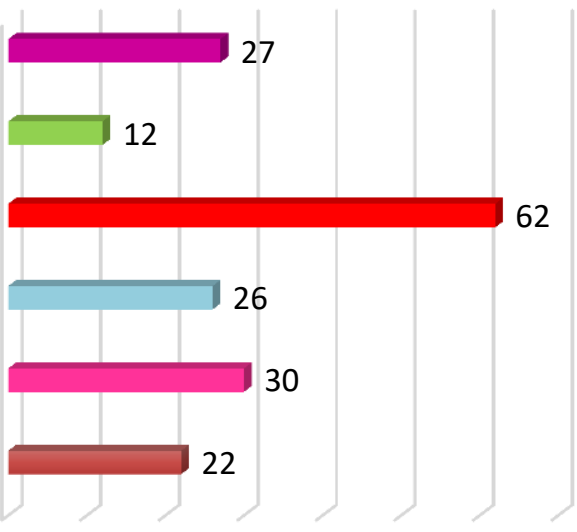

$\begin{array}{llllllll}0 & 10 & 20 & 30 & 40 & 50 & 60 & 70\end{array}$

Figure .1. Socio-cultural problems on Exclusive breast feeding 
The responses of others to various socio-cultural problems they experience as hindering the practice of EBF, (27\%) opted for interference from mother-in-law to give water, $(12 \%)$ culture of not giving water to babies together with breastfeeding, (62\%) identified pressure from family and friends as a factor, (26\%) as a misguided information from family, friends and associates on EBF. However, (30\%) informed it was a taboo for them to eat nutritious foods like jack fruit, papaya (22\%) responded superstition was a factor (Figure 1).

Respondents' information on breastfeeding was lacking since they did not have full information on how EBF ought to be rehearsed. Not having the full information on EBF and not practicing it since the mother will be ignorant of the way that she is not making the best decision and keep imperiling the life of her infant by giving lacking sustenance and its orderly outcomes; inability to flourish, poor weight gain, traded off invulnerability status, presentation to youth contaminations, and so on.

The mother also denies her body of the various benefits of exclusive breast feeding; involution of the uterus, prevention of breast and ovarian cancer, lactational amenorrhea etc. Because breastfeeding uses an average of 500 calories a day, it helps the mother lose weight after giving birth (Dewey et al., 1993). Various studies have confirmed the importance of mother's breast-feeding knowledge (Mitra et al., 2004; Avery et al., 2003; Barbara et al., 2007). Similar findings were made by Agampodi et al., (2007) on the knowledge of mothers on EBF which highlighted mother's good knowledge on EBF as the major ingredient in the successful practice of EBF.

In a study carried out in Nigeria by Okolie Uchenna (2012), on the difficulties associated with psycho-sociocultural values and investigated other problems the mothers encountered. Using a convenience sampling technique, 240 women were selected from the study population (800). The problems encountered ranged from worry and stress of feeding at all times even at night (92\%), having to breastfeed even in public places (82\%), fear that the baby might not be getting enough nutrients (71\%), to trauma of expressing breast milk (67\%), fear of safety of expressed breast milk (68\%) and a feeling that the baby will "dry up" if not given water or other fluids (50\%).

Lack of adequate education in antenatal clinics on techniques of EBF and poor education on nutrition practices for lactating mothers were evident in their responses as some of their fears were unfounded and would have been dispelled by sound health and nutrition talks. Benjamin (2011) conducted a study that practitioners especially physicians and nurses have surprising little training in lactation and lactation support.

The findings confirm that of Ramachandran (2004), who identified factors like the attitude of health workers towards lactating mothers in their practice of EBF as being unacceptable since some of these health officers lay little or no emphasis on the need for adequate nutrition of the infant till 6 months with only breast milk.

\section{CONCLUSION:}

The aim of this study was to identify the various problems encountered by breastfeeding mothers in their practice of EBF in Sri Gokulam hospital, Salem. From the findings of the study, it is clear that breastfeeding mothers face a lot of problems in their attempt to carry out exclusive breast-feeding. Hence education and proper reinforcement during antenatal period will reduce problems during lactation period.

\section{ACKNOWLEDGEMENT}

We would like to express our gratitude to all primipara mothers who gave us their precious time and invaluable information patiently and eagerly.

REFERENCES:

1) Agampodi SB, Agampodi TC, Piyaseeli UK (2007). Breastfeeding practices in a public health field practice area in Sri Lanka: a survival analysis. Int. Breastfeeding J. 11;2:

2) Benjamin RM (2011). U.S. Department of Health and Human Services. The Surgeon General's Call to Action to Support Breastfeeding. Washington DC, US.

3) Mitra AK, Khoury A, Hinton AW (2004). The influence of psychosocial factors on the duration of breastfeeding. Scand. J. Public Health 32:210-216.

4) Okolie Uchenna (2012). Problems encountered by breastfeeding mothers in their practice of exclusive breast feeding in tertiary hospitals in Enugu State, South-east Nigeria, International Journal of Nutrition and Metabolism Vol. 4(8), pp. 107 - 113, August 2012 DOI: 10.5897/IJNAM11.057

5) UNICEF (2016). https://www.unicef.org/publications/index_96412.html

6) World Health Organization (WHO), bxclusive breast feeding; http://www.who.int/Elena/titles/exclusive_breastfeedig/en/.

7) WHO, The optimal duration of exclusive breastfeeding: report of an expert consultation. Geneva: World Health Organization, Department of nutrition for health and development and department of child and adolescent health and development; 2012. 